\title{
Abstract
}

\section{FACTORS INFLUENCING QUALITY OF HEALTH MANAGEMENT INFORMATION SYSTEM (HMIS) DATA THE CASE OF KINONDONI DISTRICT IN DAR ES SALAAM REGION, TANZANIA}

\author{
Daudi O. Simba and Mughwira A. Mwangu
}

\begin{abstract}
Objective: A study was done in Kinondoni Municipality, Tanzania, to assess quality of data collected through the HMIS and explore possible associated factors.

Method: Using a structured questionnaire, health facility in-charges were interviewed. Attributes of data quality were recorded from health facility data using an observation schedule. A total of 69 health facilities were involved in the study including all (21) public health facilities and $25 \%(41 / 164)$ private facilities. Completion rate of health facility data was used as a proxy for measuring quality of data.

Results: Although knowledge on HMIS basic concept was found to be associated with improved quality of data, training in HMIS did not seem to correspond with improved quality of data. Regardless of duration, supervision had no relationship with quality of data thus raising serious doubts on its quality. Presence of a focal person, responsible for day to day HMIS activities, had a positive influence on the quality of data where facilities with a focal person had a higher data completion rate $(69.9 \%)$ compared to those without (44.7\%). Accountability as measured by queries reportedly made by Municipal authorities on data inaccuracies was associated with better quality of data. However, queries on delay in sending report had no influence in quality of data. Conclusion: The study concludes that training, followed by supervision in HMIS, did not result into a significant improvement of the quality of HMIS. There is need to re-examine the current approaches used in training and supervision to focus on actual needs of health workers. As a long- term goal, creation of demand for processed data will serve to enhance ownership of the system by health workers, hence improve data quality
\end{abstract}

Key Words: Health, Data Quality, Information System, Tanzania.

\section{Introduction}

Data that is accurate, complete and timely delivered to users is an important aspect in health planning, management and decision making (1-2). Evidence based plans and decisions must of necessity be based on accurate, complete and timely data. In response to this challenge, the Health Management Information System (HMIS), also known in Kiswahili as Mfumo wa Taarifa za Huduma za Afya (MTUHA), was started in Tanzania in the early 1990s. The introduction of the HMIS was aimed at ensuring the availability of accurate, timely and relevant data to health managers for purposes of planning and decision-making. In the designing of the HMIS emphasis was put on collecting data that was seen to be relevant for planning and decisionmaking. The HMIS covers the entire spectrum of the health care delivery system right from the health facility level, district, regional up to the national (Ministry of Health headquarters) level. Several reasons have been advanced to explain the problem of poor data quality in developing countries including failure of health workers to appreciate the importance of information and shortage of medical recorders. $(1,3)$. Other reasons included failure to respond to data received and sometimes responding only when report has not been received. The collection of enormous amount of data tends to put an unnecessary burden to data collectors (1). since most health workers lack of knowledge and skills for analyses. However, most of the reports are based on experiences accrued by experts in the course of implementing various strategies for improvement of HMIS.

Correspondences to: Daudi O. Simba, , Box 65015, School of Public Health \& Social Sciences, Muhimbili University College of Health Sciences, Tanzania

${ }^{1}$ Dept. of Community Health, ${ }^{2}$ Dept. of Development Studies, Muhimbili University College of Health Sciences (MUCHS).
This study was therefore carried out to assess factors associated with data quality with a view to proposing strategies for improving the quality of HMIS data. A number of factors that are likely to affect the quality of HMIS data were examined. These included training in HMIS, frequency and quality of supervision conducted and presence of HMIS focal person responsible for the day to day activities.

\section{Methodology}

\section{Study Sample and Population}

A cross-sectional study was conducted in Kinondoni Municipality, Dar es Salaam region, Tanzania. Kinondoni Municipality was conveniently selected since it is within Dar es Salaam where the researchers are based. The study picked a random sample of 41 private health facilities that represented $25 \%$ of all private health facilities (4), while all public and parastatal facilities were selected since their numbers were relatively smaller compared to private facilities. Altogether a total of 69 facilities were covered in this study. Table 1 shows the number of health facilities studied by ownership.

Table 1: Health facility type by ownership

\begin{tabular}{llccl}
\hline & \multicolumn{3}{l}{ Health facility ownership } \\
\hline Health facility type & $\begin{array}{l}\text { Government } \\
\text { Parastatals }\end{array}$ & $\begin{array}{l}\text { Private } \\
\text { Total }\end{array}$ \\
\hline Hospitals & 1 & 2 & 0 & 3 \\
Health centres & 2 & 1 & 1 & 4 \\
Dispensaries & 20 & 38 & 4 & 62 \\
\hline Total & $\mathbf{2 3}$ & $\mathbf{4 1}$ & $\mathbf{5}$ & 69 \\
\hline
\end{tabular}




\section{Procedures for Data Collection}

Data collection was done using a structured questionnaire which was administered to the in-charges from the 69 health facilities. Using an observation schedule, quality of data was determined from records found in registers, data books and reports for the year 2001. A pre-test was done in four health facilities to check on the relevance of data collection tools and the overall research approach. The results of the pre test were used in the preparation of the final and more refined data collection tools.

\section{Definition of terms used}

Quality of data: Quality of data refers to the degree to which the data or statistics measures what was intended to be measured when the data collection system was designed. Data quality is multidimensional with every step from designing to decision making having the ability to affect the level of quality (3). In this study, completion rate of facility data books and reports was used as a proxy for quality of data. This was necessitated by the fact that other parameters such as data accuracy could not allow comparison due to small numbers of health facilities that qualified for assessment of accuracy. Whereas, none of the private facilities had enough data for determining data accuracy, only half (10/21) of the Government facilities had. Data completeness was assessed by examining the extent to which some selected tables in the health facility data were filled. Outpatient attendances and top ten diseases respectively were deliberately selected for this purpose. The main reason for selecting outpatient services data was that these services are offered by all health facilities public, private, parastatal and others. This means that by selecting these tables we were able to capture and analyse data that cuts across all types of health facilities.

\section{Data Analysis}

Data was analyzed using EPI Info software by generating frequency and crosstabulation tables. For each variable, analysis was limited to health facilities that had adequate data. Facilities that had missing data were excluded in the analysis for that specific variable. Due to small number of health facilities owned by parastatals and the fact that most of them did not have adequate data to allow comparison these facilities were also excluded during analyses.

\section{Findings}

\section{Quality of HMIS data}

Results from the study shows that the average completion rate of the two OPD tables was $64.2 \%$, see Table 2. Completion rate was higher for government facilities $(71.6 \%)$ compared to private facilities $(54.8 \%)$.
However, these findings are based on 34 (51.5\%) facilities because the remainder of the health facilities had not filled in the data books at all. Among Government facilities, $90.5 \%$ had filled in the data books while only $36.6 \%$ of private facilities had done so.

Table 2: Completeness of Selected OPD Tables by Ownership

\begin{tabular}{|c|c|c|c|c|c|}
\hline \multirow{3}{*}{ Health facility type } & \multicolumn{4}{|c|}{ Completion rate for OPD data } & \multirow[b]{3}{*}{$\begin{array}{l}\% \\
\text { Completion }\end{array}$} \\
\hline & \multicolumn{4}{|c|}{$\begin{array}{l}\text { OPD Attendance } \\
\text { OPD Top ten diseases Total }\end{array}$} & \\
\hline & $\begin{array}{l}\text { Cells } \\
\text { Filled } \\
\end{array}$ & $\begin{array}{l}\text { Total } \\
\text { Cells } \\
\end{array}$ & $\begin{array}{l}\text { Cells } \\
\text { Filled } \\
\end{array}$ & $\begin{array}{l}\text { Total } \\
\text { cell }\end{array}$ & \\
\hline Government $(N=19)$ & 1829 & 2223 & 3162 & 4750 & 71.6 \\
\hline Private $(N=15)$ & 1221 & 1755 & 1796 & $\mathbf{3 7 5 0}$ & 54.8 \\
\hline Total/Average $(\mathrm{N}=34)$ & 3050 & 3978 & 4958 & 8500 & 64.2 \\
\hline
\end{tabular}

Relationship between Knowledge of HMIS Concepts and Quality of data

The relationship between knowledge of the concepts and quality of data was determined by eliciting understanding of five basic HMIS concepts / definitions that include Knowledge of long form of HMIS, Indicator, Numerator, Denominator and Threshold value. Knowledge of long form of HMIS by the in charge of the facility was taken as a proxy for measuring knowledge due to the higher number of respondents in both groups (with and without knowledge) a factor that allowed better comparison than other parameters used to measure knowledge. It was revealed that those with knowledge of HMIS concepts had higher completion rate in both Government $(75.7 \%)$ as well as private facilities $(73.2 \%)$ compared to those without $(49.9 \%$ for Government and $50.2 \%$ for private) as shown in table 3 .

Table 3: Knowledge of HMIS Concepts by Completion Rate.

\begin{tabular}{|c|c|c|c|c|c|c|}
\hline & \multicolumn{4}{|c|}{ Government $N=15$} & \multirow[b]{3}{*}{ Expected } & \multirow[b]{3}{*}{$\%$} \\
\hline & \multicolumn{4}{|c|}{ Private $\quad N=15$} & & \\
\hline & Filled & Expected & $\%$ & Filled in & & \\
\hline Defined & 2499 & 3303 & 75.7 & 806 & 1101 & 73.2 \\
\hline Not defined & 1099 & 2202 & 49.9 & 2211 & 4404 & 50.2 \\
\hline
\end{tabular}

\section{Influence of training in HMIS on quality of data}

Analysis was done to determine the impact of HMIS training on data quality using HMIS training status of the health facility in charge. Assumption was made that where the in charge of the facility is trained on HMIS, health staff would be able to fill in most, if not all, the tables that may appear complex for those not trained.

Whereas in Government facilities completion rate was slightly higher among those not trained (77.7\%) compared to those who received training $(69.4 \%)$ a different picture was observed in private facilities where those trained had a 
higher completion rate $(79.9 \%)$ compared to those not trained $(49.8 \%)$ - see Table 4.

Table 4: Training on HMIS by Completion Rate

\begin{tabular}{lllllll}
\hline Health facility type & \multicolumn{5}{c}{ Completion rate for OPD data } \\
\hline \multicolumn{1}{l}{ Training status } & \multicolumn{5}{c}{ Government facilities $(\mathbf{N}=\mathbf{1 9})$} \\
\hline & \multicolumn{5}{c}{ Private Faclities $(\mathbf{N}=\mathbf{1 5})$} \\
\cline { 2 - 7 } & Cells & Total & $\mathbf{\%}$ & $\begin{array}{l}\text { Cells } \\
\text { Cells }\end{array}$ & \multicolumn{1}{c}{ Total } & \% \\
& Filled & cell & \\
\cline { 2 - 7 } Trained & 3566 & 5138 & 69.4 & 1435 & 1796 & 79.9 \\
Not trained & 1425 & 1835 & 77.7 & 1582 & 3175 & 49.8 \\
\hline
\end{tabular}

\section{Association between supervision and quality of HMIS} Data

All health facilities except one private facility reported to have been supervised in the past one year. About $81.9 \%$ facilities reported to have been visited within the previous 3 months. Comparison was made between facilities supervised for half an hour and less compared to those supervised for more than half an hour during the visit. Ironically, completion rate for facilities supervised for half an hour or less was higher (73.4\%) than those supervised for more than half an hour $(60.1 \%)$ - see Table 5 .

Table 5: Duration of supervision by Completion Rate

\begin{tabular}{|c|c|c|c|c|c|}
\hline \multirow[b]{2}{*}{ Duration of supervision } & $\begin{array}{l}\text { Comp } \\
\text { OPD } \\
\text { Atten }\end{array}$ & ion rate & $\begin{array}{l}\text { D DA } \\
\text { OPD } \\
\text { Disea }\end{array}$ & p Ten & Total \\
\hline & $\begin{array}{l}\text { Cells } \\
\text { filled }\end{array}$ & $\begin{array}{l}\text { Total } \\
\text { cells }\end{array}$ & $\begin{array}{l}\text { Cells } \\
\text { filled }\end{array}$ & $\begin{array}{l}\text { Total } \\
\text { cells }\end{array}$ & $\begin{array}{l}\% \\
\text { completion }\end{array}$ \\
\hline $\begin{array}{l}\text { Half an hour and less } \\
(\mathrm{N}=15) \\
\text { More than half an hour } \\
(\mathrm{N}=18)\end{array}$ & $\begin{array}{r}1605 \\
1445 \\
\end{array}$ & $\begin{array}{r}2435 \\
2523 \\
\end{array}$ & $\begin{array}{r}1755 \\
2106 \\
\end{array}$ & $\begin{array}{r}3750 \\
4500 \\
\end{array}$ & $\begin{array}{r}73.4 \\
60.1 \\
\end{array}$ \\
\hline
\end{tabular}

\section{Influence of HMIS focal persons on quality of HMIS} data

A focal person is a health staff who has been appointed to deal with the day to day issues related to the HMIS. However, health facilities and districts were at liberty to select one among members of staff to deal with HMIS on daily basis. Analysis was done to assess whether the presence of HMIS focal person had an influence on the quality of data. It was found from this study that private facilities that had HMIS focal person had a higher completion rate $(69.9 \%)$ compared to those without (44.7\%) as shown in Table 6. Only one public facility was reported to have a focal person, therefore, comparison in this category was not possible.
Table 6: Presence of HMIS Focal Person by Completion Rate Among Private Facilities

\begin{tabular}{|c|c|c|c|c|c|}
\hline Focal Person & \multicolumn{5}{|c|}{ Completion rate for OPD data } \\
\hline Status & & \multicolumn{4}{|c|}{ Government facilities $(N=19)$} \\
\hline \multicolumn{2}{|c|}{ OPD Attendance } & \multicolumn{4}{|c|}{ OPD to Ten Diseases Total } \\
\hline & $\begin{array}{l}\text { Cells } \\
\text { Filled } \\
\end{array}$ & $\begin{array}{l}\text { Total } \\
\text { Cells } \\
\end{array}$ & $\begin{array}{l}\text { Cells } \\
\text { Filled } \\
\end{array}$ & $\begin{array}{l}\text { Total } \\
\text { cell }\end{array}$ & $\%$ \\
\hline Focal person $\mathrm{N}=6$ & 650 & 702 & 889 & 1500 & 69.9 \\
\hline No focal person $\mathrm{N}=9$ & 571 & 1053 & 907 & 2250 & 44.7 \\
\hline
\end{tabular}
whether they had been queried by the district staff for delay in sending reports and inaccuracies found in reports sent to the district. These questions were used as indicators for measuring accountability of health facility workers to the district authorities. Queries on data inaccuracies and delays in reporting were analysed against data quality using completion rates of OPD data. Table 7a shows that completion rate had no significant difference between health facilities queried for delay (59.3) compared with those that were not queried (65.7\%). On the other hand, those queried for inaccuracies had higher completion rate $(74.8 \%)$ than those not queried $(61.9 \%)$ - see Table $7 \mathrm{~b}$. Analyses could not be done by ownership of health facilities due to small sample size of both public and private facilities.

Table 7a: Proportion of facilities queried for delay on reporting by completion rate

\begin{tabular}{llllll}
\hline Query Status & & \multicolumn{5}{c}{ Completion Rate of OPD Data } \\
\hline \multicolumn{1}{c}{ OPD Attendance } & \multicolumn{4}{c}{ OPD to Ten Diseases Total } \\
\cline { 2 - 7 } & Cells & Total & Cells & Total & $\%$ \\
& Filled & Cells & Filled & cell & completion \\
\cline { 2 - 6 } & 823 & 936 & 917 & 2000 & 59.3 \\
Queried $(\mathrm{N}=6)$ & 2227 & 3042 & 4041 & 6500 & 65.7 \\
Not queried $(\mathrm{N}=25)$ & & &
\end{tabular}

Table 7b: Proportion of Facilities Queried for Inaccuracies by Completion Rate

\begin{tabular}{llllll}
\hline Query Status & \multicolumn{5}{c}{ Completion Rate of OPD Data } \\
\hline \multicolumn{1}{c}{ OPD Attendance } & \multicolumn{5}{c}{ OPD to Ten Diseases } \\
\cline { 2 - 6 } & $\begin{array}{l}\text { Cells } \\
\text { Filled }\end{array}$ & $\begin{array}{l}\text { Total } \\
\text { Cells }\end{array}$ & $\begin{array}{l}\text { Cells } \\
\text { Filled }\end{array}$ & $\begin{array}{l}\text { Total } \\
\text { cell }\end{array}$ & $\%$ \\
\cline { 2 - 6 } & 665 & 702 & 983 & 1500 & 74.8 \\
Queried $(\mathrm{N}=6)$ & 2385 & 3276 & 3975 & 7000 & 61.9 \\
Not queried $(\mathrm{N}=39)$ & & & & & \\
\hline
\end{tabular}

\section{Discussion}

Knowledge of the HMIS concepts was found to be associated with better quality of HMIS data and yet this was not true of training on HMIS. This shows that, understanding the basic HMIS concepts might not be related to the basic training on HMIS. It has been reported that often training is not the problem; instead it is probably 
a manifestation of unwillingness to fill in the forms and lack of commitment and accountability of the poorly supervised health workers (5).

Supervision, regardless of the reported duration, had been shown in this study to have no relationship with improved data completion. This raises some doubts on the quality of supervision provided by Council Health Management Teams (CHMT) to the health facility workers. Except for monitoring the number of visits made by members of CHMT to the facilities, there is no mechanism for measuring and monitoring quality of supervision at health facilities as well as at district level. Thus the onus of ensuring that supervision is done effectively, is left to the supervisor.

This study has shown that the presence of HMIS focal person facilitates data processing hence improving the quality of data. However, this study did not go further into assessing the merits and demerits of having an HMIS focal person. Given that team approach is an integral part of Primary Health Care (PHC) strategy (6) delegation of HMIS duties to one person might undermine integration of the system into other programmes.

Accountability as measured through queries made by district officials on data received from health facilities revealed an association with better quality of data, however, this was not the case with query on delay of reporting. This might indicate that Municipal health workers are keen to receive reports irrespective of their quality in order to satisfy the needs of higher authorities. It has been reported that data is often collected in order to meet bureaucratic obligations rather than performance monitoring (7).

\section{Conclusions and Recommendations}

Contrary to expectations, training and supervision did not seem to influence quality of HMIS data. Some fundamental questions are raised from this study with regards to the effectiveness of HMIS training as well as the quality of supervision conducted at health facility and Municipal levels. Are training opportunities offered according to actual needs? How effective are supervision visits in improving health workers performance in HMIS? If lack of knowledge is not the main problem but a manifestation of reluctance to perform on the part of health staff, then training alone might not solve the problem (5). This calls for a need to revise approaches so as to make training on HMIS part and parcel of continuing education at the workplace and incorporated in career development of the respective staff. Mechanisms should be introduced for monitoring effectiveness of supervision using performance indicators instead of number of supervision visits.
This study has established that knowledge of the HMIS concepts and presence of a focal person earmarked to deal with HMIS issues on daily basis had an influence of improving the quality of HMIS data. This calls for the revival of medical recorders cadre whose duties includes day to day management of data in health facilities. However, this strategy should go hand in hand with developing capacity for health managers to utilize HMIS data for performance improvement. Otherwise, there is a danger of generating data for the sake of it and creating complacency among health managers who might feel that HMIS is the responsibility of the medical recorders alone.

\section{Acknowledgement}

The authors wish to thank the Muhimbili University College of Health Sciences for financial support. Also, the Kinondoni Municipality Health Management Team and the incharges of the respective health facilities for their cooperation in this study.

\section{References}

1. Robey JM and Lee SH. Information system development in support of national health programme monitoring and evaluation: The case of Philippines. World Health Stat Q 1990; 43: 37 - 43.

2. Garner P, Harpham $T$ and Annett $H$. Information support for urban primary health care. World Health Forum 1992; 13: 244-248.

3. Shrestha LB, Bodart C. Data transmission, data processing and data quality. In: Lippeveld T, Sauerborn $R$ and Bodart $C(E d s)$. Design and implementation of health sytems. Geneva: WHO ;2000

4. Kielman, A. Assessing health needs, services and systems: Protocol for rapid data collection. London: AMREF and MaCmillan Company 1995.

5. Finau SA. National health information system in the Pacific islands: In search of a future. Health Policy Plan 1994; 9 (2): 161-170.

6. Boerma T. The viability of the concept of a primary health care team in developing countries Soc Sci Med 1987; 25(6):747-52.

7. Feldman MS and March JG. Information in organization as signal and symbol. Admin Sc Q 1981; 26(1):171-186. 